\title{
Dos clássicos na literatura aos clássicos na sociologia e na sociologia médica/saúde
}

\section{| ${ }^{1}$ Everardo Duarte Nunes |}

Resumo: Neste trabalho, revisitamos a noção de clássicos a partir da literatura, retomamos o tema no campo da sociologia e estendemos esta ideia para a sociologia médica/saúde. Analisamos algumas das noções desenvolvidas por diversos autores - Gellius, Sainte-Beuve, Twain, T. S Elliot, Borges, Calvino, Merton, Schwartzman, Baehr - e discutimos a possibilidade da aplicação dessa noção em campos mais recentes, como o da sociologia médica/saúde/ doença. Apontamos a coexistência, na atualidade, de noçôes de "clássicos" na tradição do século XVII (os "escolhidos", "modelos de ensino", "modelos de linguagem”) às noçôes de modelos eternos e universais (século XIX) e à de "autoridade" (século XX). Ressaltamos o caráter de reelaboração e de aplicação do "clássico" a uma nova situação. Nesse sentido, entendemos sua extensão ao campo da sociologia da saúde.

> Palavras-chave: clássicos; precursores; pioneiros; literatura; sociologia; sociologia da saúde.

\author{
1 Saúde Coletiva, \\ Universidade Estadual de \\ Campinas. Campinas-SP, \\ Brasil. Endereço eletrônico: \\ evernunes@uol.com.br
}

Recebido em: 19/12/2014 Aprovado em: 14/04/2015 


\section{Introdução}

A questão dos clássicos não é assunto recente, mas envolve polêmicas e discordâncias. $\mathrm{Na}$ atualidade, o que se entende por clássicos ampliou-se e generalizou-se. Adiantamos que muitas vezes essa noção não é totalmente clara e se confunde ou se alterna com as noções de fundadores, precursores, pioneiros, canônicos, consagrados, vanguardistas, sendo utilizada tanto na história das artes como das ciências, das humanidades, da literatura e se inscreve hoje na linguagem popular.

Neste trabalho, revisitamos a noção de clássicos a partir da literatura, retomamos o tema no campo da sociologia e estendemos esta ideia para a sociologia médica/saúde. Analisamos algumas das noções desenvolvidas por diversos autores - Gellius (1927), Sainte-Beuve (1850), Twain (1900), E. S Elliot (1975), Borges (1952), Calvino (1993), Merton (1968), Schwartzman (2000), Baehr (2002) - e discutimos a possibilidade da aplicação dessa noção em campos de formação mais recentes.

\section{O que é um clássico a partir da literatura}

Iniciamos a história da noção de clássicos com Aulus Gellius, cujos dados biográficos não são muito precisos, incluindo o local de nascimento. Para alguns autores, suas origens seriam africanas. Por inferências, parece provável que tenha nascido cerca de 123 d.C. e falecido logo depois de 169 d.C.. Consta que viajou para a Grécia e retornou a Roma, onde escreveu Noctes Atticae, um conjunto de anotações sobre gramática, história e filosofia. Em um dos trechos, aparece a expressão classicus para designar o escritor que poderia ser considerado modelo em sua atividade - "classicus adsiduusque aliquis scriptor, non proletarius". $\mathrm{O}$ termo origina-se do adjetivo latino classicus, que indicava o cidadão pertencente à classe mais elevada de Roma, o cidadão por excelência, que pertencia à primeira das cinco classes em que os romanos se dividiam de acordo com seus patrimônios, sendo que os de classe inferior (infra classem) eram denominados proletários. Para Gellius (1927), de forma metafórica, o escritor classicus era aquele que escrevia para a classe dos mais favorecidos social e politicamente e era, por isso, um escritor notável e exemplar. 
[...] apenas um autor que era estudado (em sala de aula), independente de seu mérito. No renascimento, somente os principais trabalhos de autores gregos e latinos [...]. Hoje em dia, existe a tendência de usar o termo clássico num destes três sentidos: (a) de primeira classe ou notável; (b) antigo; (c) típico" (Cuddon apud HENRIQUES, 1997, p. 90).

Adiantamos esses comentários, mas vamos detalhar alguns estudos sobre a questão dos clássicos.

Deve-se a Charles Augustin Sainte-Beuve [1804-1869] (1850)² esclarecedora análise sobre a trajetória do termo: "Um clássico, de acordo com o senso comum, é um autor antigo, já consagrado pela admiração, é uma autoridade em seu estilo particular" (p. 38). Refere-se ao significado que os romanos davam ao termo, anota que os gregos não tiveram outros clássicos além deles próprios, discorre sobre clássicos italianos, espanhóis e franceses. Cita duas definições encontradas no Le Dictionnaire de l'Académie, de 1694 e 1835, com as quais não concorda ao asinalarem: "autor muito antigo, já consagrado pela admiração, e com autoridade na matéria que ele trata" e "aqueles que se tornaram modelos em qualquer idioma” (p. 41). Sainte-Beuve acha que já é "tempo de renunciar a essas definições restritivas e tímidas e expandir a mente”. E assim, propõe:

Um verdadeiro clássico, como gostaria que o definissem, é um autor que enriqueceu o espirito humano, que realmente aumentou o seu tesouro, que o fez avançar um passo adiante, que descobriu alguma verdade moral inequívoca, ou que recuperou alguma paixão eterna no coração, onde tudo parecia já conhecido e explorado; que expressou seu pensamento, sua observação, ou sua invenção, sob uma forma não importa a qual, desde que seja mais ampla e maior, refinada e sensível, saudável e bela em si mesma; que a todos falou num estilo peculiar, um estilo que é acessível para ser também o de todo o mundo, num estilo novo, mas sem neologismos, novo e antigo, facilmente contemporâneo, para todos os tempos (p. 42).

Sainte-Beuve define pela primeira vez em termos modernos o classicismo literário e apresenta como clássicos 38 nomes e dois livros bíblicos (Livro de Jó e Cântico dos Cânticos). ${ }^{3}$

Concluindo, escreve:

Aqui estão os nossos clássicos; a imaginação de cada um pode completar o nosso projeto e mesmo escolher seu grupo preferido. Pois é preciso escolher, e a primeira condição do gosto, depois de tudo haver compreendido, e não viajar sem cessar, mas assentar-se para fixar as ideias. [...]... quando falo de fixar e de escolher, não significa 

mos nossas escolhas com nossos próprios instintos. Tenhamos a sinceridade e espontaneidade dos nossos próprios pensamentos, dos nossos sentimentos [...] (p. 53-54).

Para Sainte-Beuve, o clássico se define ao longo do tempo, pois alguns que na sua época pareciam clássicos ("clássicos precoces") deixam de sê-lo para a posteridade e diz que "os mais imprevistos (imprevus) são ainda os melhores e os maiores". (p. 49, 50).

Cinquenta anos depois de Sainte-Beuve, o escritor Mark Twain [1835-1910] (1900) em Disappearance of Literature, discursa sobre a literatura do início do século XX citando o Professor Winchester ${ }^{4}$ sobre a sobrevivência dessa literatura e se "teria vida tão longa quanto as novelas de Walter Scott". Cita também, desse professor, que não existiam épicos modernos como o Paraíso Perdido, pondo em dúvida se alguém na plateia teria lido esse livro. Nessa altura, ele acrescenta: "Ele é um clássico, como diz o Professor Winchester, e junta a sua definição de um clássico - algo que todos querem ter lido e ninguém quer ler”. Anterior a essa citação, Twain (1898) havia escrito o aforismo: "Clássico. Um livro que as pessoas elogiam e não leem".

Depois de Saínte-Beuve, meio século mais tarde, Jorge Luiz Borges [18991986] inicia seu ensaio dizendo da inutilidade de se buscar a etimologia das palavras e as origens latinas, e que na idade em que estava não consultaria as definições anteriores; limitar-se-ia ao que havia pensado sobre o assunto. Seu exemplo é da literatura chinesa, citado por Herbert Allen Giles (1901), onde leu que "um dos cinco textos canônicos editados por Confúcio é o Livro das Mutaçôes, ou I Ching [...]", e confessa que "[d] eliberadamente escolhi um exemplo extremo, uma leitura que demanda um ato de fé”. Por fim, anota:

"Clássico é aquele livro que uma nação ou um grupo de nações ou o longo tempo decidiram ler como se em suas páginas tudo fosse deliberado, fatal, profundo como o cosmo e passível de interpretaçôes sem fim". Explica que as decisões variam de um país para outro e que a beleza literária é comum a muitos autores e pode estar presente "nas casuais páginas do medíocre ou em um diálogo de rua". Borges encerra seu texto dizendo que "clássico não é um livro (repito) que necessariamente possui estes ou aqueles méritos; é um livro que as gerações dos homens, instadas por diversas razões, leem com prévio fervor e com misteriosa lealdade" (BORGES, 1952, s/p). 
Sem dúvida, a preocupação com o significado do termo irá acompanhar muitos autores que se dedicaram a compreender o que é um clássico. Balz Engler (1988/89, p. 217) aponta que, ultimamente, a crítica tem discutido pouco a questão, e que o debate sobre a "canon-formation" tem se voltado para "como os textos literários são empregados no exercício de poder social em lugar de como os trabalhos literários tornam-se aceitos pelos seus significados universais". Toma como referência a análise do What is a classic?, de T. S. Eliot [1888-1965]. Para Eliot, "a palavra tem e continuará tendo diversos significados em diferentes contextos. Eu estou interessado em um significado em um contexto" (ELIOT, 1975, p. 115).

Engler comenta que essa ideia cria uma ambiguidade: a palavra não tem um núcleo comum de significado, mas de outro lado, que os vários contextos nos quais ela aparece são responsáveis pelos diferentes significados. Outro ponto, assinalado por Engler (1988/89, p. 219) é que "[e]m cada abordagem da literatura o clássico é definido diferentemente de acordo com o esquema conceitual no qual é situado, e cada definição deixa diferentes problemas não resolvidos". Eliot escolhe como exemplo paradigmático de clássico universal o poeta romano Virgílio (70 a.C.-19 a.C.), distinguindo-o do que chama um "autor padrão" (p. 116). Em Virgílio, identifica as duas características de um clássico: maturity (maturidade) e comprehensiveness (abrangência). Textualmente:

Se existe uma palavra sobre a qual podemos firmar que pode sugerir o máximo do que eu entendo pelo termo "um clássico", esta palavra é maturidade. Eu distinguiria entre o clássico universal, como Virgílio, e o clássico que é único somente em relação à literatura de sua própria língua ou de acordo com a concepção de vida de um período particular (p. 116).

Para Eliot, a ocorrência de um clássico somente se daria quando "uma civilização está madura, quando uma língua e uma literatura estão maduras, e isso deve ser o trabalho de um espírito maduro". Introduz, aqui, a ideia de que é a "amplitude da mente do poeta individual, que assegura a universalidade". Repetiria, com ênfase, esta ideia ao afirmar: "O clássico deve expressar, dentro de suas limitaçôes formais, o máximo possível do conjunto de sentimentos que representam o caráter das pessoas que falam aquela língua [...]. Quando um trabalho de literatura tem, além desta abrangência em relação a sua própria língua, igual significância em relação a uma série de literaturas estrangeiras, podemos dizer que ela tem também universalidade" (p. 128). Eliot fundamenta sua ideia de que as qualidades de um 
clássico servem como padrão para julgar obras literárias e não aplicar esta regra “tende a nos tornarmos provincianos" (p. 129).

Para Engler (1988/89, p. 221, 222), há três problemas com a abordagem de Eliot: o primeiro, relacionado à sua visão da história - uma ordem ideal e uma perspectiva idealista dos "monumentos" literários; o segundo, a rigidez da ordem ideal, sistema fechado - [clássico] o produto mais amadurecido e abrangente; o terceiro relaciona-se à definição das qualidades que se espera de um clássico, que são difíceis de serem descritas, segundo o próprio Eliot, e que não podem ser percebidas por todos, mas por uma "single élite" porque ela teria as mesmas características de um clássico - maturidade e abrangência.

Garcia Jurado (2010, p. 290) escreve que "em realidade, até os anos oitenta do século XX não encontramos uma reformulação absolutamente nova de 'clássico', que virá precisamente pelas mãos do escritor Ítalo Calvino".5

Em Por que ler os clássicos, Calvino [1923-1985] elenca 14 definições acerca dos clássicos seguidas de comentários (CALVINO, 1993). Diferentemente de seus predecessores, não traça significados, mas oferece uma espécie de guia para leituras, quando declara: 'O 'seu' clássico é aquele que não pode serlhe indiferente e que serve para definir a você próprio em relação e talvez em contraste com ele". Ao comentar, Calvino diz: "Creio não ter necessidade de justificar-me se uso o termo 'clássico' sem fazer distinções de antiguidade, de estilo, de autoridade", mas que ela se distingue "com um lugar próprio na comunidade cultural" (p. 13-14). Lembre-se que Eliot havia escolhido a Eneida, de Virgílio, como o clássico paradigmático, e essa "tradição clássica" vinha sofrendo desde o final dos anos quarenta uma abalizada análise crítica, quando já se percebe a "convivência desta com tradiçôes e correntes propriamente modernas” (GARCIA JURADO, 2010, p. 289).

Segundo Garcia Jurado (2010, p. 291), “frente ao caráter aristocrático das primeiras formulações de 'clássico' e também contra o caráter proletário das mais recentes (em particular o proletarius, não classicus de Harry Levin) Calvino aposta decididamente por uma imagem de uma biblioteca particular de leituras ligadas à vida”. Certamente, esta é uma das liçôes de Calvino. Mas, há outras: a distinção entre o leitor da idade madura (mais detalhista, com possibilidade de mais comparações) e o jovem (mais particularista, mais impaciente); reencontro 
com antigas leituras, quando já não somos os mesmos; os significados de ler

e reler livros que surpreendem pelas descobertas que suscitam e "se revelam novos, inesperados, inéditos" (p. 12); mais ainda, se revelam como um talismã; provocam "um barulho de fundo" imprescindível e "persiste(m) como rumor mesmo onde predomina a atualidade mais incompatível” (p. 15).

\section{Clássicos da sociologia}

A questão dos clássicos não é menos complexa quando vista a partir da sociologia. Aqui, novas categorias aparecem; entre elas a de precursores, fundadores e pioneiros. Não é estranho, portanto, que Merton [1910-2003], em muitos momentos de seus trabalhos, tenha tratado da questão, mas especialmente em Sobre a história e a sistemática da teoria sociológica (MERTON, 1968). Nesse texto denso e provocativo, Merton cita como epígrafe a frase do filósofo e matemático britânico Alfred North Whitehead [1861-1947]: "Uma ciência que hesita em esquecer seus fundadores está perdida”.

Para Schwartzman (1982, p. 151), com essa citação Merton tinha em mente

[...] desenvolver uma linguagem autônoma e precisa para as ciências sociais [que], permitiria a formulação de preposições suscetíveis de teste empírico e a emergência gradativa de uma disciplina madura, respeitável, e tão distante da linguagem comum e da especulação filosófica quanto a física moderna.

Segundo Merton (1968, p. 18), os sociólogos mantinham “uma concepção limitada e vaga da história das ideias" diferente dos novos historiadores que estavam aparecendo (o texto foi escrito em 1949).

Ao desenvolver ideias como as de redescobrimento e pré-descobrimento, antecipaçôes e prefiguraçôes, Merton assinala:

[...] o contraste entre a orientação das ciências para os grandes trabalhos clássicos e a orientação das humanidades. [...] Nas ciências mais exatas, a acumulação seletiva do conhecimento significa que as contribuições clássicas feitas por homens de gênio ou de grande talento, são amplamente desenvolvidas em obras posteriores, muitas vezes, por homens de talento muito menor [...]. Nas humanidades, cada trabalho clássico - cada poema, drama, romance, ensaio ou trabalho histórico - sendo observado diretamente, tende a continuar fazendo parte da experiência direta das sucessivas gerações de humanistas [...] o primeiro contato com os clássicos desempenha papel insignificante no trabalho dos cientistas da física, da biologia, mas tem grande importância no trabalho dos estudiosos de humanidades (p. 40, 41). 
Ao recorrer a Weber, Merton prossegue seu raciocínio sobre acumulação, assimilação e expansão da ciência, quando o sociólogo alemão analisa a obsolescência do conhecimento científico e escreve "não é só nosso destino, como também nosso objetivo, que sejamos cientificamente superados" (WEBER, 1992, p. 438).

Para Merton, há sociólogos que se prendem às contribuições clássicas; alguns se adaptam às pressões e caminham pelas sugestões weberianas e a maioria "oscil(a) entre as duas posições e poucos são os que procuram consolidá-las” (MERTON, 1968, p. 42). Em dois momentos, Merton avança sobre a questão dos clássicos: quando trata da Erudição versus originalidade e as Funçôes da teoria clássica. No primeiro, aponta que muitas vezes têm ocorrido "uma tendência em reverenciar indiscriminadamente qualquer afirmação feita pelos famosos ancestrais" (p. 43). Daí, a epígrafe de Whitehead que ele colocou em seu trabalho. Outra tendência é a banalização, a citação frequente e inconsequente das teorizações dos antecessores. No segundo item, chama a atenção para o fato de que, se na física e na biologia pode-se, por exemplo, ignorar Newton e Darwin, "o sociólogo, mais como sociólogo do que como historiador da sociologia, tem amplos motivos para estudar os trabalhos de Weber, Durkheim e Simmel e até mesmo para remontar, ocasionalmente, às obras de Hobbes, Rousseau, Condorcet e Saint-Simon" (p. 48). Cita também que "outra função dos clássicos é a de proporcionar um modelo para o trabalho intelectual" [...] "formar padrões de critério e julgamento para identificar um bom problema sociológico” (p. 49); são livros que fecundam, dignos de serem relidos de quando em quando, e que desenvolvem "novas ideias por meio do retorno aos velhos textos dentro do contexto do conhecimento contemporâneo" (p. 50). Sentimos que neste momento Merton estava reabilitando o pensamento clássico.

Em 1998, o Congresso Mundial de Sociologia, da International Sociological Association (ISA), realizado em Montreal, tematizou a avaliação crítica da herança sociológica do século XX e apresentou uma pesquisa de opinião para identificar os dez livros mais influentes para os sociólogos. Pediu-se aos membros da ISA que listassem cinco livros publicados no século XX que os haviam influenciado. Participaram da pesquisa $16 \%$ dos membros (455/2.785). Os resultados estão na tabela 1 e evidenciam que alguns dos "clássicos" do século XIX e primeiros anos do século XX estão ausentes. 
Tabela 1. Relação de autores, obras e votos da pesquisa da ISA - 1997

\begin{tabular}{|c|c|c|c|}
\hline & Autores & Título & Votos \\
\hline 1 & Weber, Max & Economy and Society & $95(20,9 \%)$ \\
\hline 2 & Mills, Charles Wright & The Sociological Imagination & $59(13,0 \%)$ \\
\hline 3 & Merton, Robert K. & Social Theory and Social Structure & $52(11,4 \%)$ \\
\hline 4 & Weber, M. & $\begin{array}{l}\text { The Protestant Ethic and the Spirit of } \\
\text { Capitalism }\end{array}$ & $47(10,3 \%)$ \\
\hline 5 & $\begin{array}{l}\text { Berger, P.L. e } \\
\text { Luckmann, T. }\end{array}$ & The Social Construction of Reality & $45(9,9 \%)$ \\
\hline 6 & Bourdieu, Pierre & $\begin{array}{l}\text { Distinction: A Social Critique of the } \\
\text { Judgment of Taste }\end{array}$ & $43(9,5 \%)$ \\
\hline 7 & Elias, Norbert & The Civilizing Process & $30(6,6 \%)$ \\
\hline 8 & Habermas, Jürgen & The Theory of Communicative Action & $29(6,4 \%)$ \\
\hline 9 & Parsons, Talcott & The Structure of Social Action & $28(6,2 \%)$ \\
\hline 10 & Goffman, Erving & The Presentation of Self in Everyday Life & $25(5,5 \%)$ \\
\hline
\end{tabular}

Fonte: ISA - International Sociological Association. Books of the Century, Disponível em: $<$ http://www.isa-sociology.org/books/>

Antes dessa pesquisa, muitos sociólogos desenvolveram análises sobre os chamados fundadores e pioneiros da sociologia. Raymond Aron [1967](1987) separa os "fundadores" - Montesquieu [1689-1755], Augusto Comte [17911857], Karl Marx [1818-1883], Alexis de Tocqueville [1805-1859] dos "mestres contemporâneos" em lugar de chama-los de "autores clássicos” - Émile Durkheim [1858-1917], Vilfredo Pareto [1848-1923], Max Weber [1864-1920] no que denomina "uma galeria de retratos intelectuais" (p. 11).

Em data recente, Outhwaite (2009) tratou, como ele designa, do status "canônico" que quatro sociólogos alcançaram na sociologia britânica, no final do século passado, transformando o espaço teórico da sociologia na Grã-Bretanha. São eles: Zygmunt Bauman [1926], Ulrich Beck [1944], Pierre Bourdieu [19302002] e Anthony Giddens [1938]. Diríamos que são os "novos clássicos". Para o autor, todos esses pensadores, podem ser agrupados na mesma coorte geracional profissional e que ao retomarem em suas obras os clássicos, especialmente Marx, 
tornaram possível, citando Skinner (1985) que “[esses] clássicos parecessem menos como ancestrais remotos e mais como contemporâneos mais velhos" (OUTHWAITE, 2009, p. 1031).

Nessa linha de pesquisa, Schwartzman (2000) analisa a sociologia no Brasil no século XX e realiza uma enquete entre cientistas sociais. Dos 49 que responderam, dez eram sociólogos, 13 eram cientistas políticos, 14 eram economistas, seis eram antropólogos e os demais historiadores e pessoas da área do direito, da filosofia e da administração. Cada respondente indicou até cinco obras mais importantes e cinco mais influentes. Quando não foi feita a distinção, a obra foi considerada importante e influente.

Tabela 2. Principais autores nas ciências sociais do século XX (Brasil)

\begin{tabular}{|c|c|c|c|c|c|c|c|c|c|c|}
\hline \multirow{2}{*}{ Autores } & \multicolumn{2}{|c|}{ total } & \multicolumn{2}{|c|}{ economistas } & \multicolumn{2}{|c|}{ sociólogos } & \multicolumn{2}{|c|}{ c. políticos } & \multicolumn{2}{|c|}{ antropólogos } \\
\hline & influência & mérito & influência & mérito & influência & mérito & influência & mérito & influência & mérito \\
\hline $\begin{array}{l}\text { Gilberto } \\
\text { Freyre }\end{array}$ & $44,9 \%$ & $44,9 \%$ & $28,6 \%$ & $28,6 \%$ & $50,0 \%$ & $50,0 \%$ & $46.2 \%$ & $53,9 \%$ & $66,7 \%$ & $50,0 \%$ \\
\hline $\begin{array}{l}\text { Celso } \\
\text { Furtado }\end{array}$ & $42,9 \%$ & $44,9 \%$ & $92,9 \%$ & $85,7 \%$ & $0,0 \%$ & $0,0 \%$ & $53,9 \%$ & $61,5 \%$ & $0,0 \%$ & $0,0 \%$ \\
\hline $\begin{array}{l}\text { Raymundo } \\
\text { Faoro }\end{array}$ & $34,7 \%$ & $34,7 \%$ & $28,6 \%$ & $35,7 \%$ & $20,0 \%$ & $10,0 \%$ & $38,5 \%$ & $38,5 \%$ & $50,0 \%$ & $50,0 \%$ \\
\hline $\begin{array}{l}\text { Sérgio } \\
\text { Buarque de } \\
\text { Hollanda }\end{array}$ & $34,7 \%$ & $28,6 \%$ & $35,7 \%$ & $35,7 \%$ & $20,0 \%$ & $20,0 \%$ & $53,9 \%$ & $15,4 \%$ & $33,3 \%$ & $50,0 \%$ \\
\hline $\begin{array}{l}\text { Victor } \\
\text { Nunes Leal }\end{array}$ & $20,4 \%$ & $24,5 \%$ & $7,1 \%$ & $0,0 \%$ & $20,0 \%$ & $20,0 \%$ & $38,5 \%$ & $46,2 \%$ & $33,3 \%$ & $50,0 \%$ \\
\hline $\begin{array}{l}\text { Florestan } \\
\text { Fernandes }\end{array}$ & $10,2 \%$ & $20,4 \%$ & $14,3 \%$ & $14,3 \%$ & $20,0 \%$ & $20,0 \%$ & $7,7 \%$ & $23,1 \%$ & $16,7 \%$ & $33,3 \%$ \\
\hline $\begin{array}{l}\text { Caio Prado } \\
\text { Júnior }\end{array}$ & $18,4 \%$ & $20,4 \%$ & $28,6 \%$ & $28,6 \%$ & $10,0 \%$ & $10,0 \%$ & $23,1 \%$ & $30,8 \%$ & $0,0 \%$ & $0,0 \%$ \\
\hline $\begin{array}{l}\text { Oliveira } \\
\text { Viana }\end{array}$ & $16,3 \%$ & $16,3 \%$ & $0,0 \%$ & $0,0 \%$ & $10,0 \%$ & $10,0 \%$ & $46,2 \%$ & $23,1 \%$ & $6,7 \%$ & $33,3 \%$ \\
\hline $\begin{array}{l}\text { Euclides da } \\
\text { Cunha }\end{array}$ & $14,3 \%$ & $14,3 \%$ & $7,1 \%$ & $7,1 \%$ & $0,0 \%$ & $0,0 \%$ & $15,4 \%$ & $15,4 \%$ & $33,3 \%$ & $33,3 \%$ \\
\hline
\end{tabular}

Fonte: Schwartzman, S. Ciência (2000). Reproduzida com a autorização do autor.

Analisando os dados, o autor aponta que esses autores e suas obras propóem o Brasil como tema e a proposta de uma nova visão do país, mas mostram "uma 
sociedade sem atores, sem iniciativas, no máximo com instituições precárias,

e populações vivendo as consequências e o peso de seus determinismos". Como escreve, os livros sobrevivem, mas a maior parte das teorias propostas por seus autores são relíquias do passado (luso-tropicalismo, homem cordial, determinismos geográficos e raciais de nossa organização). Outra questão referese aos "consensos" e às "diferenças", quando são comparadas as respostas entre sociólogos, economistas e cientistas políticos No final do artigo, o autor pergunta: para que servem os clássicos? A resposta de Schwartzman:

Pela presteza com que a enquete foi respondida, e a pouca dificuldade que tiveram as pessoas em atender ao pedido de no máximo cinco referências em cada categoria, acredito que esses autores continuam bem presentes na mente de nossos cientistas sociais, definindo suas questões e apontando caminhos e descaminhos para a busca de respostas

E conclui que "as ciências podem sempre buscar no passado os temas de diálogo e de renovação”.

Lembramos que Goldthorpe (1971, p. 10), ao prefaciar o livro de Timothy Raison ([1962], 1971), escreveu que um ponto paradoxal era que a obra dos precursores

[...] não forma de fato, de maneira alguma, parte da história da sociologia, ao contrário, ela ainda é a sociologia dos dias de hoje, uma vez que os tópicos substantivos discutidos e os problemas de teoria e método que surgem são ainda cheios de vida e permanecem como pontos focais de debate e das pesquisa contemporâneos.

Devedores que somos a muitas das contribuições desses autores, não podemos deixar de assinalar que a análise realizada por Peter Baher (2002) é sem dúvida uma das mais instigantes ao confrontar as noções de fundador, cânone e clássico tanto para os autores como para os textos. Selecionamos do livro o que nos parece mais pertinente às nossas questões. Assim, ao traçar a "herança” de um campo, devemos considerar os "eventos", os "objetos" e os "processos" que incluem ou excluem determinadas obras; o exemplo estudado pelo autor é a criação do L'année Sociologique, por Durkheim, em 1896. Outro ponto é que a emergência de "clássicos" envolve a identificação e avaliação de textos tratados como objetos de prestígio e fonte de análises. $\mathrm{O}$ autor reuniu quatro fatores que descrevem o processo de recepção/formação de um clássico: ressonância cultural, flexibilidade textual, apropriação pelo leitor, transmissão e difusão. Segundo Baher, devem ser vistos sincronicamente - implicam-se mutuamente - e diacronicamente - cada formação clássica demanda tempo, especialmente para difusão e transmissão. 


\section{Clássicos da sociologia da saúde}

De um modo geral, os trabalhos, ao analisarem o campo da sociologia médica/ saúde, não utilizam a noção de clássicos. Recentemente, Chaiklin (2011) adotou o que ele chama de "trabalho dos pioneiros". Nessa categoria, inclui: Henderson, Cannon, Stern, Straus, Bloom, Syme, House, Elling e Mechanic. Outro trabalho que oferece algum encaminhamento ao tema é de Chard, Lilford, Court (1997). Nele os autores levantam a questão das relações entre epidemiólogos e cientistas sociais, a partir de trabalho sobre a pesquisa qualitativa no campo da sociologia médica. Analisam 782 artigos, tendo como fontes os artigos citados no MEDLINE, BIDS and Psyclit e em textbooks, e elaboram uma lista de 100 trabalhos qualitativos em sociologia médica que denominam de "top" e uma "star galery" dos vinte mais citados trabalhos. Constam dessa lista: Goffman (2 vezes), Parsons, Starr, Freidson, Illich, Antonovisky, Szasz, Foucault (2 vezes), Kleimann (duas vezes), McKeown, Becker, Parkes, Scheff, Martin, Verbrugge, Rosenhan, Pearlin.

Concordamos com muitos desses nomes, mas como mostraremos a seguir, há outros que devem ser citados. De outro lado, adotamos uma categoria anterior aos pioneiros, a dos autores que fixaram algumas ideias que consideramos estar nas origens do campo. São precursores. Entre eles, os médicos: John Shaw Billings [1838-1913], Charles McIntire (1894), que usou pela primeira vez a expressão sociologia médica, ${ }^{6}$ Elizabeth Blackwell [1821-1910], James Peter Warbasse [1866-1957], e o empresário, filantropo e pesquisador social Charles Booth [1840-1916]. Todos foram despertados pelas questôes sociais lato sensu relacionadas a medicina, higiene, saúde pública, profissão médica e educação médica, mas esses primeiros estudiosos, não avançaram na disciplinarização da sociologia médica. O mesmo se aplica a autores europeus, por exemplo, os médicos Louis René Villermé [1782-1863] e Alfred Grotjan [1869-1931] e o advogado Edwin Chadwick [1800-1890], cujas importantes observações sobre a doença e organização de práticas sanitárias se tornaram destaques para a história da saúde pública. Na América Latina, a mesma situação se repete, e entre os muitos exemplos citamos Eugenio Espejo [1747-1795] (Equador), Gustavo Molina [1910-1978] (Chile) e Samuel Pessoa [1898-1976] (Brasil).

Do ponto de vista sociológico, o principal trabalho a ser incluído no grupo de textos fundadores seria o estudo sobre o suicídio, publicado em 1897 por Durkheim [1858-1917]. Atente-se também para a originalidade da análise de 
Engels [1820-1895] sobre a classe trabalhadora na Inglaterra, publicado em 1845 (ENGELS, 2008).

A importância dos "clássicos" da sociologia e do que chamamos precursores no trato das questôes da saúde e doença tem sido retomada de maneira diferente daqueles estudiosos que achavam, genericamente, que não havia ocorrido interesse sociológico entre os clássicos por esses temas. Para Collyer (2012, p. 6), "seria completamente errado sugerir que todos escritos sociológicos caem nessa armadilha. Há exceçôes muito importantes, incluindo Michel Foucault, cujas teorias sugerem um passado comum para a sociologia e a medicina". Lembra a autora que em Nascimento da clínica, Foucault "teorizou a formação da medicina e da sociologia modernas como consequência de uma mudança epistêmica”.

Em nossa busca arqueológica sobre as origens do campo, encontramos que a partir de determinado momento começam a aparecer autores cujos interesses aproximam-se mais especificamente das ciências sociais. Nesse sentido, mencionamos o importante papel pioneiro desempenhado pela Escola de Sociologia de Chicago, que transformou a cidade de Chicago, nas primeiras décadas do século XX, em um "laboratório natural" de investigação de problemas sociais, lançando mão de estratégias teóricas (teoria dos círculos concêntricos) e de metodologias variadas (survey, entrevistas, coleta de dados estatísticos, levantamentos históricos). Segundo Becker (1996, p. 3), ela se caracterizava muito mais como uma "escola de atividade", que ele define como "um grupo de pessoas que trabalham em conjunto, não sendo necessário que os membros da escola de atividade compartilhem a mesma teoria; eles apenas têm de estar dispostos a trabalhar juntos". Foi desse cenário que saíram as primeiras pesquisas sobre a distribuição da doença mental na cidade de Chicago sob a orientação de Robert E. Park (FARIS; DUNHAM, 1939). Segundo Bloom (2002, p. 68-74), esse trabalho se tornou fundamental para se entender a chamada hipótese "ecológica", cartografando a distribuição residencial de todos os pacientes admitidos nos hospitais públicos e privados de Chicago, encontrando alta concentração ao redor da área central de comércio.

Esses estudos foram antecedidos por trabalhos que também categorizamos como pioneiros. Citamos o sociólogo e antropólogo Bernhard J. Stern [18941956], o historiador Henry E. Sigerist [1891-1957] e o bioquímico e sociólogo Lawrence J. Henderson [1878-1942]. 
Stern nasceu em Chicago, recebeu os graus de bacharel e mestre pela Universidade de Cincinnati e desde cedo voltou-se para a sociologia. Durante sua permanência na Europa (1923-1924), ingressou na escola de medicina da Universidade de Graz, mas por motivos de saúde desistiu dessa opção de carreira; frequentou a Universidade de Berlim e a London School of Economics. Matriculouse na Universidade de Columbia em 1924, onde, sob a influência de Franz Boas e William Fielding Ogburn (seu supervisor de tese), completou o doutorado em sociologia e antropologia, com a tese Social factors in medical progress. Stern dedicou-se a diversos temas - cultura, medicina, saúde, história do pensamento, família e hereditariedade - assumindo uma perspectiva materialista histórica em suas pesquisas. A importância de sua obra para a sociologia da saúde pode ser vista em dois trabalhos que são paradigmáticos da sua extensa produção: The physician and society ([1948] 1959) e Toward a sociology of medicine ([1951] 1959). Straus (1978, p. 309) considera Stern o "pai” da sociologia médica, observando que muitos anos antes desse campo ser assim identificado, ele "testou e estendeu a teoria sociológica e as formas pelas quais os cientistas sociais podiam reinterpretar a história, esclarecer os processos e, mesmo, predizer o futuro da medicina”. Esta impregnação teórica está presente desde sua tese, quando ele anuncia:

A presente pesquisa está interessada em dois aspectos da mudança cultural como ela ocorre no campo da medicina, a primeira, uma análise dos fatores psicológicos e sociológicos que retardam a difusão das inovações, e segundo, a natureza do progresso na medicina (STERN, 1927, p. 7).

Como avalia Bloom (2002, p. 97), nesse trabalho Stern "afirmava a prioridade da estrutura social no desenvolvimento do conhecimento".

O historiador Sigerist, contemporâneo e amigo de Stern, além de ter se dedicado à história da medicina, foi pioneiro ao tratar do doente, em artigo de 1929, The special position of the sick. Trata-se de ensaio histórico-teórico que seria retomado por vários estudiosos (NUNES, 1999).

Incluímos, entre os pioneiros, Henderson, que vindo de uma formação que passou pela medicina, química, fisiologia, influenciado por Pareto, voltou-se para a sociologia. Parsons, Merton, Homans e outros cientistas sociais serão devedores de suas ideias. De importância para a sociologia médica, citamos o seu trabalho Physician and patient as a social system, no qual estabelece:

Duas pessoas [médico e paciente] e não há necessidade de outras mais, constituem um sistema social. Estes indivíduos são heterogêneos. Eles têm e são movidos por 
sentimentos e interesses. Eles conversam e raciocinam. Esta é uma definição. Agora

estabelecerei um teorema. Em qualquer sistema social os sentimentos e as interações entre os sentimentos são provavelmente os mais importantes fenômenos. Este é o meu segundo ponto (HENDERSON, 1935, p. 820).

Sem dúvida, entre 1930-1960, os pioneiros lançaram os primeiros estudos no campo da sociologia médica que se desenvolveria com grande força nas décadas seguintes em diversas universidades norte-americanas.

Parsons constrói a partir de Harvard onde esteve de 1927-1973, toda sua obra, incluindo sua análise sobre a prática médica e a relação médico-paciente (PARSONS, 1951); em Colúmbia, Merton (1957) elabora os estudos sobre a socialização do estudante de medicina; em Yale são realizados estudos sobre a doença mental nas grandes cidades (SROLE, 1962) e as relações entre doença mental e classe social (HOLLINGSHEAD; REDLICH, 1958), e na mesma universidade Robert Straus já havia apresentado seu doutorado em 1947, considerado um dos primeiros no campo da sociologia médica. Dez anos depois (STRAUS, 1957), analisaria a divisão da sociologia médica em sociologia na e da medicina; em Harvard, Fox (1959) escreve o emblemático trabalho de pesquisa qualitativa em uma enfermaria de pacientes com problemas metabólicos; na Universidade de Kansas, Becker e colaboradores (1961) realizam o estudo exemplar sobre a carreira de estudantes de medicina; na Baylor University, Bloom (1963) elabora o primeiro livro que aborda o ensino da sociologia para estudantes de medicina, a partir do relacionamento médico-paciente, resultado de sua experiência na Escola Médica dessa universidade.

Interessante observar que alguns trabalhos que aparecem na década de 1960, tanto nos Estados Unidos como Europa, passarão a ser referências no campo da sociologia médica, embora seus autores não se identifiquem como sociólogos médicos. Referimo-nos a Goffman [1922-1982], em Asylmuns (1961) e Stigma (1963), e Foucault, com História da Loucura (1961) e O nascimento da clínica (1963).

A partir de 1970, novos enfoques e temas atravessaram a sociologia médica nos Estados Unidos, mas sem dúvida, o destaque foi Eliot Freidson (1970) e seu estudo, que se tornaria paradigmático para as análises da profissão médica. Durante essa década, a sociologia médica completou seu processo de institucionalização, e em 1976 a Medical Sociology Section da American Sociological Association criou um prêmio para distinguir os mais importantes pesquisadores no campo, denominado, 
a partir de 1978, Leo G. Reeder Award. São 38 autores que têm seus nomes inscritos na história da sociologia médica, muitos partícipes das origens do campo, como Straus, Fox, Bloom, Strauss, Hollingshead, etc. e outros de uma geração mais recente, como Conrad, House, Waitzkin, Pescosolido, etc. cujos trabalhos trazem novos elementos conceituais e teóricos na permanente (re)configuração da sociologia em suas relações com a saúde/doença/cuidado (NUNES, 2014).

\section{Considerações finais}

Baher (2001, p. 142), ao escrever Classicality: criteria and reception, anota "a natureza da classicalidade é estratificada entre os ramos do conhecimento assim como dentro deles”. Para ele, citando Alan How (1998, p. 830) “o objeto de análise para o estudante de literatura é o texto literário clássico que estrutura o cânone... para o sociólogo o cânone é o meio através do qual o objeto, a sociedade, é vista”. Assinala outras diferenças, mas parece que aqui reside um ponto importante, retomado por Olsen (1996, p. 78, apud BAHER, 2002, p. 148), quando afirma que uma obra literária passa necessariamente por um "processo de apreciação" e uma obra sociológica por um "processo de assimilação". Acrescenta Baher (2002, p. 144) que a avaliação do clássico em sociologia é um processo interno, feito por especialistas, membros da comunidade acadêmica e que no julgamento literário e artístico haveria "potencialmente e de fato duas audiências" - "os especialistas da cultura e o público (s) não acadêmicos”.

Ao trazermos para o final estas observações, com as quais concordamos, não estamos marginalizando o que foi exposto na primeira parte - os clássicos a partir da literatura. Em realidade, torna-se difícil qualquer síntese sobre a questão dos clássicos na literatura, embora possamos encontrar alguns pontos comuns. Os "clássicos" podem ser vistos como referência ou como modelo; são os "escolhidos", os consagrados, erigidos como "modelos para o ensino", "modelos de linguagem”, na tradição do século XVII, aos quais se junta a noção do século XIX de modelos eternos e universais.

Segundo Vaila (2005, p. 394, 395), essas definições do passado ainda "coexistem" nos dias de hoje e "um legado do emprego inicial, a tentação de fazer dos clássicos 'autoridades', tem sobrevivido”. García-Jurado (2010, p. 277, 292) escreve que, se de um lado, a concepção de "clássico" de Gellius não corresponde ao que hoje se entende com esse nome; de outro, no século XX ocorre "uma 
ruptura dos cânones e os autores clássicos já não representam uma convenção herdada, mas uma escolha pessoal onde o [caráter] aleatório também intervém".

Da mesma forma, muitas das observações desenvolvidas pelos autores que estudaram os clássicos da sociologia são pertinentes quando nos deslocamos para outros campos do conhecimento.

Consideramos que a síntese de Shils (1980, p. 247) é oportuna, quando escreve que a função de um clássico nas ciências sociais “não é para ser assimilado, superado, e considerado fora de moda, como nas ciências naturais, mas para ser elaborado, adaptado, colocado em um novo idioma, aplicado a uma nova situação”. Essa é uma ideia forte para o campo da sociologia da saúde, interdisciplinar em essência e que tem acolhido uma temática extremamente diversificada que trabalha com o processo saúde-doença, mas que estende as teorias e conceitos sociológicos para o cuidado em saúde e suas práticas.

\section{Referências}

ARON, R. As etapas do pensamento sociológico. São Paulo: Martins Fontes, 1987.

BAEHR, P. Founders, classics, canons: modern disputes over origins and appraisal sociology's heritage. New Brunswick, NJ: Transaction Publishers, 2002.

BECKER, H. S. A Escola de Chicago. Mana, v.2, n.2, p. 177-188, 1996.

BECKER, H. S. et al. Boys in White: student culture in medical school. Chicago: The University of Chicago Press; 1961.

BLOOM, S. W. The doctor and his patient: a sociological interpretation. New York: Russell Sage, 1963.

BLOOM, S. W. The word as a scapel: a history of Medical Sociology. Nova York: Oxford University Press, 2002.

BORGES, J. L. Sobre los clásicos. In: . Otras inquisiciones. Buenos Aires: Sur, 1952.

CALVINO, I. Italiani, vi esorto ai classici. L’Espresso. 28 giugno 1981, p. 58-6.

CALVINO, I. Peché leggere i classici. Milano: A. Mondadori, 1991.

CALVINO, I. Por que ler os clássicos. São Paulo: Companhia das Letras, 1993.

CECATO, C. Comentários gramaticais de Aulo Gélio: uma proposta de tradução. Dissertação (Mestrado) - Universidade Federal do Paraná, Curitiba, 2005. Disponível em: <http://www. classicas.ufpr.br/projetos/dissertacoes/CleuzaCecatoComentariosGramaticaisDeAuloGelio. pdf.> Acesso em: 3 jun. 2012.

CHAIKLIN, H. The state of the art in medical sociology. The Journal of Nervous and Mental Disease, v. 199, n. 8, p. 585-591, 2011. 
CHARD, J. A.; LILFORD, R. J.; COURT, B. V. Qualitative medical sociology: what is its crowning achievement. Journal of Royal Society of Medicine, v. 90, n. 11, p. 604-609, 1997. COLLYER, F. Mapping the sociology of health and medicine: America, Britain and Australia compared. Houndmills: Palgrave Macmillan, 2012.

DURKHEIM, E. O suicídio: um estudo sociológico. Rio de Janeiro: Zahar, 1982.

ELIOT, T.S. Address to the Virgil Society on October 16, 1944; In: . Selected prose of T. S. Eliot. New York: Houghton Mifflin Harcourt, 1975.

ENGELS, F. A situação da classe trabalhadora na Inglaterra. São Paulo: Boitempo, 2008.

ENGLER, B. The classic as a public symbol. Real: Yearbook of research in English and American Literature, 6, 1988/1989, p. 217-236. Disponível em: <http:/www.balzengler.ch/ files/classic_as_a_public_symbol.pdf>. Acesso em: 05 maio 2011.

FARIS, R. L.; DUNHAM, H. W. Mental disorders in urban areas. Chicago, University of Chicago Press, 1939.

FOUCAULT, M. História da Loucura. São Paulo: Perspectiva, 1978 [1961].

FOUCAULT, M. O nascimento da clínica. Rio de Janeiro: Forense Universitária, 1977 [1963].

FOX, R. C. Experiment perilous: physicians and patients facing the unknown. Philadelphia: University Press; 1974 [1959].

FREIDSON, E. The profession of medicine: a study of the sociology of applied knowledge. New York: Dodd, Mead and Company, 1970.

GARCIA JURADO, F. La ciudad invisible de los clásicos. Entre Aulo Gelio e Italo Calvino. Nova Tellus, v. 28, n. 1, p. 271-300, 2010 . Disponível em: <:http://redalyc.uaemex.mx/src/ inicio/ArtPdfRed.jsp?iCve=59115484009>. Acesso em: 5 maio 2011 .

GELLIUS, A. Nocticum Athicarum - Liber XIX, seção 8, parágrafo 15. Loeb Classical Libray, 1927. Disponível em: <http//penelope.uchicago.edu/Thayer/L/Roman/Texts/ Gellius/19*.html>. Acesso em: 13 maio 2011.

GOFFMAN, E. Asylums: essays on the social situation of mental patients and other inmates. New York: Anchor Books, 1961.

GOFFMAN, E. Stigma: notes on the management of spoiled identity, Englewood Cliffs, NJ: Prentice-Hall, 1963.

GOLDTHORPE, J. H. Introdução. In: RAISON, T. Os precursores das ciências sociais. São Paulo: Zahar, 1971, p 10-17.

HENDERSON, L. J. The patient-physician as a social system. New England Journal of Medicine, v. 212, p. 819-823, 1955.

HENRIQUES, C. C. Sob o signo dos clássicos. Matraga, 9, 1997, Disponível em: <www. pgletras.uerj.br/matraga/matraga09/matraga9a07.pdf>. Acesso em: 5 maio 2014. 
HOLLINGSHEAD, A. B.; REDLICH, F. C. Social class and mental illness: a community study. New York: John Wiley \& Sons; 1958.

HOW, A. That's classisc! A Gademaerian defence of the classics text in sociology. Sociological Review, v. 46, n. 4, p. 828-848, 1998.

McINTIRE, C. The importance of study of medical sociology. Bulletin of the American Academy of Medicine, n. 19, p. 425-434, February 1894.

MERTON, R. K. Sobre a história e a sistemática da teoria sociológica. In:

Sociologia: teoria e estrutura. São Paulo: Mestre Jou, 1968, p. 17-50.

MERTON, R. K.; READER, G.; KENDALL, P. L. The Student-Physician: introductory studies in the sociology of medical education. Cambridge: Harvard University Press, 1957.

NUNES, E. D. Da posição do doente na sociedade: texto de Sigerist de 1929. In:

Sobre a sociologia da saúde: origens e desenvolvimento. São Paulo: Hucitec, 1999. p. 45-58.

NUNES, E. D. Os premiados: a sociologia médica/saúde na perspectiva do Leo G. Reeder Award (1977-2010), 2014, 220 p. (mimeo).

OLSEN, S. H. The concept of literary canon. Annals for Aesthetics, v. 36, p. 71-84, 1996.

OUTHWAITE, W. Canon formation in late 20th-century British Sociology. Sociology, v. 43, n. 6, p. 1029-1045, 2009.

PARSONS, T. The Social System. Glencoe, IL:The Free Press, 1951.

RAISON, T. Os precursores das ciências sociais. São Paulo: Zahar, 1971.

SAINTE-BEUVE, C. A. Da tradição à literatura. Salvador: Livraria Progresso, 1957.

SAINTE-BEUVE, C. A. Qu'est-ce qu'un classique. Le Constitutionnel, 21 oct. 1850.

Disponível em: <http://www.tierslivre.net/litt/lundi/classique.PDF>. Acesso em: 9 jun. 2012.

SCHWARTZMAN, S. Quem tem medo do Estado? In: LAMOUNIER, B. (Org.). A ciência política nos anos 80. Brasília: EdUnB, 1982, p. 151-155.

SCHWARTZMAN, S. As ciências sociais brasileiras no século 20. Ciência Hoje, 2000.

Disponível em: <http://www.schwartzman.org.br/simon/10mais.htm>. Acesso em: 9 jun. 2012.

SHILLS, E. The trend of sociology. In: The calling of sociology and other essays on the pursuit of learning. Chicago: University of Chicago Press, 1980.

SIGERIST, H. E The special position of the sick. In: ROEMER, M. I. Henri E. Sigerist on the sociology of medicine. Nova York: MD Publications, 1960 [1929]. p. 9-22.

SROLE, L. et al. Mental health in the metropolis. New York, McGraw-Hill, 1962.

STERN, B. J. The physician and society toward a sociology of medicine. In:

Historical sociology: selected papers. Nova York: Citadel Press, 1959 [1948]. p. 395-418. 

papers. Nova York: Citadel Press, 1959 [1951], p. 419-424.

STRAUS, R. The nature and status of medical sociology. American Sociological Review, v. 22, n. 2, p. 200-204, 1957.

STRAUS, R. Becoming and being a medical behavioral scientist. In: ELLING, R. H.; SOKOLOWSKA, M. Medical Sociologists at Work. New Brunswick: Transaction Publishers, 1978, p. 309-335.

TWAIN, M. Disappearance of literature. Address at the Dinner of the Nineteenth Century Club, Sherry's, New York, 20 Nov. 1900. Speeches. Disponível em: <http://www.fullbooks. com/Mark-Twain-s-Speeches3.html>. Acesso em: 16 maio 2011.

TWAIN, M. Following the Equator: a journey around the world. Hartford: The American Publishing Company, 1898. Disponível em: <http://www.gutenberg.org/files/2895/2895h/2895-h.htm>. Acesso em: 16 maio 2011.

VAILA, A. Lire les classiques au temps de la mondialisation. Revue XVIIe siècle, v. 228, n. 3, p. 393-407, 2005. Disponível em: <www.cairn.info/revue-dix-septieme-siecle-2005-3page-393.htm>. Acesso em: 21 set. 2014.

WEBER, M. A ciência como vocação. In: Metodologia das ciências sociais. São Paulo: Cortez, 1992, p. 431-453.

\section{Notas}

${ }^{1} \mathrm{O}$ trecho completo é o seguinte: "Ite ergo nunc et, quando forte erit otium, quaerite, an 'quadrigam' et 'harena' dixerit e cohorte illa dumtaxat antiquiore vel oratorum aliquis vel poetarum, id est classicus adsiduusque aliquis scriptor non proletarius". (GELLIUS, 1927). A tradução de Cecato (2005, p. 212) é a seguinte: "Vão, e quando tiverem tempo, procurem se quadrigae e harenae (no plural) são encontradas em algum poeta, ou orador, que não seja proletário, que ocupe um lugar nas filas da antiga corte (sic)". 2 Trabalhamos com o texto original (SAINTE-BEUVE, 1850) cotejando nossa tradução com a de Pinto Aguiar (SAINTE-BEUVE, 1957).

${ }^{3}$ Para Sainte-Beuve, são clássicos: Homero, Valmiki, Vyasa, Firdusi, Sólon, Hesíodo, Teógnis, Xenofonte, Platão, Sófocles, Demóstenes, Confúcio, Virgílio, Menandro, Tíbulo, Terêncio, Horácio, Ovídio, Lucrécio, Dante, Bocaccio, Ariosto, Torquato Tasso, Montaigne, Malherbe, La Fontaine, Corneille, Pascal, Bossuet, Molière, Shakespeare, Swift, Cervantes, Milton, Voltaire, Goethe e dois livros bíblicos - o Livro de Jó e o Cântico dos Cânticos.

${ }^{4}$ Caleb Thomas Winchester (1847-1920), bibliotecário da Connecticut Wesleyan University de 1869 a 1885 e professor de Retórica e Literatura Inglesa de 1873 a 1920.

${ }^{5} \mathrm{O}$ texto original de Calvino Italiani, vi esorto ai classici, apareceu no L Espresso, 28/ junho/1981. Posteriormente, publicado no livro Perché leggere i classici (Calvino, 1991), sendo a edição brasileira de 1993.

${ }^{6}$ Além desse trabalho, o primeiro a utilizar a expressão "medical sociology", Charles McIntire publicou The expanse of sociologic medicine (Journal of Sociologic Medicine, v. 16, p. 1-3, 1915). Esse periódico substituiu o Bulletin of American Academy of Medicine e publicou apenas alguns números. 


\section{Abstract}

From classic literature to the classics in sociology and medical sociology / health

In this paper, we revisit the notion of classics from the literature, we return to the topic in the field of sociology and extend this idea to the medical / health sociology. We have analyzed some of the concepts developed by several authors - Gellius, Sainte-Beuve, Twain, T. S Elliot, Borges, Calvino, Merton, Schwartzman, Baehr and discussed the possibility of applying this notion in more recent fields, such as medical sociology / health / disease. We've pointed out the coexistence, nowadays, of notions of "classic» in the tradition of the 17th century (the "chosen», «teaching models», «language models») to notions of eternal and universal models (19th century) and of «authority» (20th century). We emphasize the character of redesigning and implementing the "classic» to a new situation. In this sense, we understand its extension to the field of sociology of health.

> Key words: classic; precursors; pioneers; literature; sociology; sociology of health. 